\title{
ANTIBACTERIAL ACTIVITIES, DFT AND QSAR STUDIES OF QUINAZOLINONE COMPOUNDS
}

\author{
Abdullah G. Al-Sehemi ${ }^{1,2,3}$, Ahmad Irfan ${ }^{1 *}$, Sulaiman A. Alrumman ${ }^{4}$ and Abd El-Latif Hesham ${ }^{4}$ \\ ${ }^{1}$ Department of Chemistry, Faculty of Science, King Khalid University, Abha 61413, P.O. Box \\ 9004, Saudi Arabia \\ ${ }^{2}$ Research Center for Advanced Materials Science, King Khalid University, Abha 61413, P.O. \\ Box 9004, Saudi Arabia \\ ${ }^{3}$ Unit of Science and Technology, Faculty of Science, King Khalid University, Abha 61413, \\ P.O. Box 9004, Saudi Arabia \\ ${ }^{4}$ Department of Biology, Faculty of Science, King Khalid University, Abha 61413, P.O. Box \\ 9004, Saudi Arabia
}

(Received November 12, 2014; revised February 25, 2016)

\begin{abstract}
The quinazolinone compounds (1 and 2) in this work were examined for their in vitro antibacterial activities against gram-positive (Staphylococcus aureus) and gram-negative bacteria (Klebsiella pneumonia, Proteus bacilli and Shigella flexneri). Compared to the reference antibiotic chloramphenicol, these compounds showed high antibacterial activities against studied strains with inhibition zones observation. The ground state geometries have been optimized by using density functional theory (DFT) at B3LYP/6-31G* level of theory. The absorption spectra have been calculated by using time dependent density functional theory (TDDFT) with and without solvent. The effect of different functionals (B3LYP, MPW1PW91, and PBE1PBE) on the absorption wavelengths has been studied. The ionization potential (IP), electron affinity (EA), energy gap ( $\mathrm{E}_{\text {gap }}$ ), electronegativity $(\chi)$, hardness $(\eta)$, electrophilicity $(\omega)$, softness $(S)$ and electrophilicity index $(\omega i)$ were computed and discussed. The nonlinear optical (NLO) properties vary by changing the theory (DFT to HF) or functional (B3LYP to CAM-B3LYP). The physicochemical parameters have been studied by quantitative structure-activity relationship (QSAR). The computed properties of investigated compounds have been compared with the Chloramphenicol as well as available experimental data.
\end{abstract}

KEY WORDS: Antibacterial activity, Density Functional Theory, Time Dependent Density Functional Theory, Charge transfer, Quantitative structure-activity relationship

\section{INTRODUCTION}

The quinazolinone derivatives are good compounds which have been intensively used as biologically active compounds, e.g. anticancer, antibacterial, anticonvulsant, anti-inflammatory, antiulcer and analgesic [1-3]. The quinazolines derivatives have been synthesized and characterized as active candidates [4]. Previously, the compounds $\mathbf{1}$ and $\mathbf{2}$ have been synthesized [5] and characterized, see Figure 1.

In the present study, our aim is to investigate the antibacterial activity of $\mathbf{1}$ and $\mathbf{2}$. Moreover, to the best of our knowledge, no quantum chemical study about the electronic, spectroscopic, charge transfer properties, nonlinear optical properties (NLO) and quantitative structure-activity relationship (QSAR) have been carried out so far. In this work, the structural and electronic properties were investigated by density functional theory (DFT) which has been used intensively and proved an efficient approach [6,7]. The photophysical properties were studied by time dependent DFT (TDDFT). The effect of B3LYP, MPW1PW91 and PBE1PBE functionals have been studied on the absorption wavelengths [8-11]. The light was shed on the chemical properties on the basis of computed descriptors, i.e. ionization potential (IP), electron affinity $(E A)$, energy gap $\left(E_{\text {gap }}\right)$, electronegativity $(\chi)$, hardness $(\eta)$, electrophilicity $(\omega)$, softness $(S)$ and

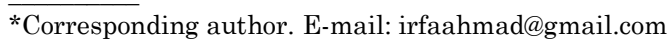


electrophilicity index $(\omega \mathrm{i})$. The NLO properties have been computed by using ab-initio Hartree Fock (HF) and DFT (B3LYP and CAM-B3LYP) methods to investigate the effect of theory as well as functional. In addition, the computed data was compared with the available experimental data and reference compound (chloramphenicol). Finally, this study focuses on the importance of quinazolinone as active compounds for antibacterial activity, chemical descriptors, and physicochemical parameters such as refractivity and partition coefficients $(\log \mathrm{P})$.

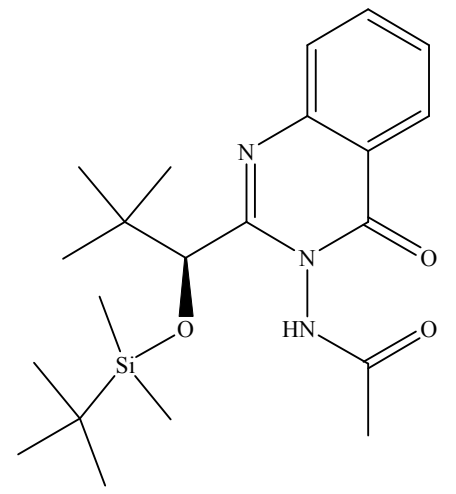<smiles>O=C1CCC2=Nc3ccccc3C(=O)C2N1</smiles>

Figure 1. The investigated compounds 1 (left) and $\mathbf{2}$ (right).

\section{EXPERIMENTAL}

\section{Materials and methods}

The newly synthesized compounds were tested for their in-vitro antibacterial activity against four pathogenic bacterial species representing both gram-positive and gram-negative strains. The representatives of gram positive strain was Staphylococcus aureus while Klebsiella pneumonia, Proteus bacilli and Shigella flexneri were the representatives of gram negative strains. All the synthesized compounds were screened for antibacterial activity against pathogenic bacterial by agar diffusion method at the concentration of $100 \mathrm{mg} / \mathrm{mL}$ in dimethyl sulfoxide (DMSO). Antibiotic chloramphenicol used as standard for antibacterial activity [12, 13]. The zone of inhibition was measured in $\mathrm{mm}$ and the activity was compared with standard.

\section{Computational details}

Recently, we have optimized the geometries of organic compounds different compounds by using B3LYP functional and proved that it is reliable approach to reproduce the experimental data $[8,14-19]$. The absorption wavelengths have been computed by using TD-DFT [20, 21]. Furthermore, the absorption spectra have also been computed in DMSO by using the Polarized Continuum Model (PCM) [22]. In the first step, absorption wavelengths have been computed at B3LYP/6-31G* and B3LYP/6-31+G* level of theory. No significant effect has been observed on the absorption spectra by changing the basis set basis thus B3LYP/6-31G* level of theory was used for further calculations. The effect of B3LYP, MPW1PW91 and PBE1PBE functionals on the absorption wavelengths has been investigated. Non-linear optical properties have been computed at HF/6-31G*, B3LYP/6-31G* and CAM-B3LYP/6-31G* level of theories. The reactivity descriptors have been computed by DFT approach from the Eqs. 1-5 [23,24]. Mulliken electronegativity $(\chi)$ was calculated from Eq. 1: 
$\chi=\left(\mathrm{E}_{\mathrm{HOMO}}+\mathrm{E}_{\mathrm{LUMO}}\right) / 2$

The hardness $(\eta)$ was computed by using Eq. 2:

$\eta=\left(\mathrm{E}_{\mathrm{LUMO}}-\mathrm{E}_{\mathrm{HOMO}}\right) / 2$

Electrophilicity $(\omega)$ was calculated from the following Eq.:

$\omega=\left(\mathrm{E}_{\mathrm{HOMO}}+\mathrm{E}_{\mathrm{LUMO}} / 2\right)^{2} / 2 \eta$

Softness (S) was calculated as:

$\mathrm{S}=1 / 2 \eta$

Electrophilicity index ( $\omega$ i) was calculated from the following equation:

$\omega \mathrm{i}=\mu^{2} / 2 \eta$

The adiabatic ionization potential (IPa) and vertical ionization potential (IPv) have been calculated as [25]:

$\mathrm{IPa}=\mathrm{E}^{0}(\mathrm{X})^{+}-\mathrm{E}^{0}(\mathrm{X}) \quad$ and $\quad \mathrm{IPv}=\mathrm{E}^{1}(\mathrm{X})^{+}-\mathrm{E}^{0}(\mathrm{X})$

The ground state energies of the neutral and charged (cation) states represented by $E^{0}(N)$ and $\mathrm{E}^{0}(\mathrm{~N})^{+}$, respectively, and $\mathrm{E}^{1}(\mathrm{~N})^{+}$is the energy of charged (cation) state at the optimized geometry of the neutral molecule. The adiabatic/vertical electron affinity (EAa)/(EAv) of all molecules have been calculated as under;

$\mathrm{EAa}=\mathrm{E}^{0}(\mathrm{~N})-\mathrm{E}^{0}(\mathrm{~N})^{-}$and $\mathrm{EAv}=\mathrm{E}^{0}(\mathrm{~N})^{-} \mathrm{E}^{1}(\mathrm{~N})^{-}$

Here, $E^{0}(N)$ corresponds to the ground state energies of the neutral and $E^{0}(N)^{-}$is the energy of charged (anion) states. The term $E^{1}(\mathrm{~N})^{-}$represents the energy of charged (anion) state at the optimized geometry of the neutral molecule. All these calculations were performed by Gaussian09 software [26]. For QSAR study; the coordinates of optimized geometries at B3LYP/6-31G* level of theory were selected. The physiochemical properties were computed by AM1 and DFT implemented in Hyperchem [27].

\section{RESULTS AND DISCUSSION}

\section{Antibacterial activities}

The antibacterial activities of $\mathbf{1}$ and $\mathbf{2}$ have been reported in the Table 1. In this study, the results of antibacterial tests demonstrated that $\mathbf{1}$ was most active against Staphylococcus aureus, Klebsiella pneumonia, Proteus bacilli and Shigella flexneri with inhibition zone 33, 29, 39 and $25 \mathrm{~mm}$, respectively, while 26, 40, 25 and $25 \mathrm{~mm}$, respectively, for 2 . The antibacterial activities of the compounds were high and moderate when compared with the reference antibiotic chloramphenicol, $30 \mu \mathrm{g} / \mathrm{mL}$. From the results it was observed that 1 exhibited high activity against all the organisms employed and moderate activity against Shigella flexneri. On the other hand $\mathbf{2}$ exhibited high activity against all the organisms employed and moderate activity against Staphylococcus aureus. 
Table 1. Antibacterial ${ }^{*}$ activity of the synthesized compounds.

\begin{tabular}{|l|l|l|l|l|}
\hline Compounds & S. aureus & P. bacilli & \multicolumn{3}{|c|}{ S. flexneri K. pneumonia } \\
\hline $\mathbf{1}$ & 33 & 39 & 25 & 29 \\
\hline Antibiotic & 28 & 12 & 30 & 26 \\
\hline $\mathbf{2}$ & 26 & 25 & 25 & 40 \\
\hline Antibiotic & 32 & 23 & 22 & 11 \\
\hline
\end{tabular}

${ }^{*}$ Zone of inhibition was measured in $\mathrm{mm}$.

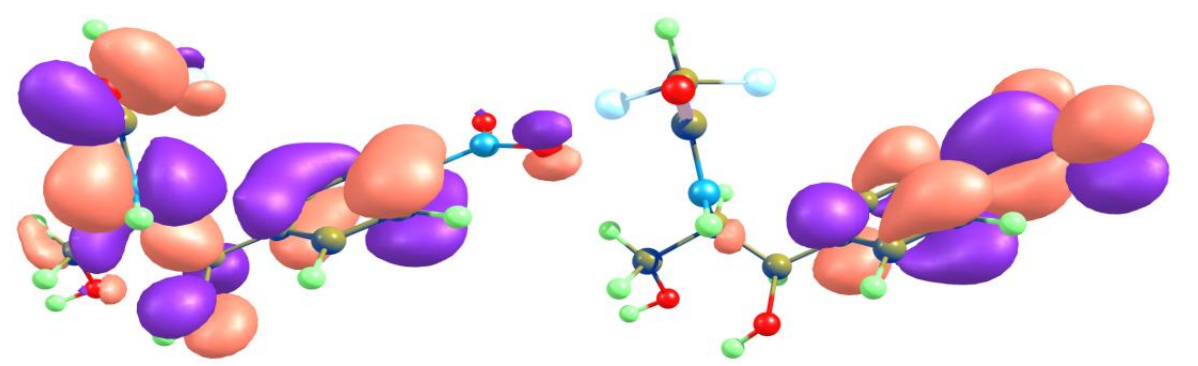

Chloramphenicol
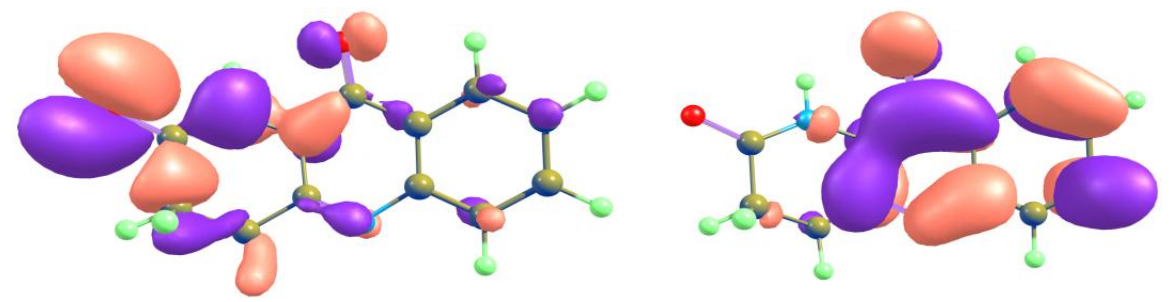

2

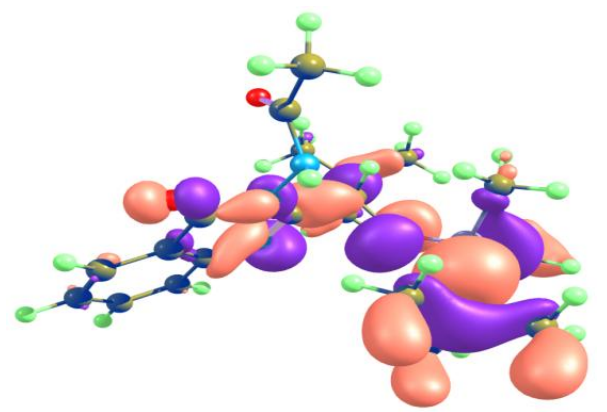

1

HOMO

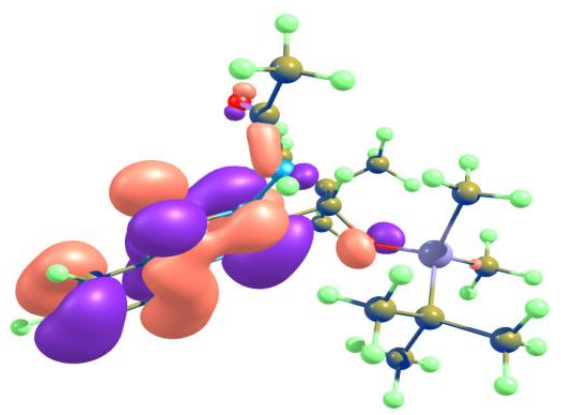

LUMO

Figure 2. Distribution pattern of the HOMO and LUMO of $\mathbf{1}, \mathbf{2}$ and chloramphenicol at B3LYP/6-31G* level of theory.

Electronic properties and absorption spectra

Figure 2 illustrates the distribution pattern of the highest occupied molecular orbitals (HOMOs) and lowest unoccupied molecular orbitals (LUMOs). The HOMO is delocalized throughout the 
system while LUMO is localized on nitro-phenyl ring in chloramphenicol. The distribution pattern revealed the intra-molecular charge transfer from HOMO to LUMO in chloramphenicol. In 1, HOMO is distributed on most of the system except acetyl group and benzene moiety while quinazolinone moiety is taking part in the formation of LUMO. The intra-molecular charge transfer has been observed from Si side to quinazolinone moiety in 1. In 2, the HOMO is distributed on the left side of the compound while LUMO is spread over the quinazolinone moiety. The intra-molecular charge transfer has also been observed from HOMO to LUMO. The HOMO energies ( $\left.\mathrm{E}_{\mathrm{HOMO}}\right)$, LUMO energies $\left(\mathrm{E}_{\mathrm{LUMO}}\right)$ and HOMO-LUMO energy gaps $\left(\mathrm{E}_{\text {gap }}\right)$ at B3LYP/6-31G* level of theory have been tabulated in Table 2. A large $E_{\text {gap }}$ implies a high kinetic stability and low chemical reactivity, because it is energetically unfavorable to add electrons to a high-lying LUMO or to extract electrons from a low-lying HOMO. The $\mathrm{E}_{\mathrm{HOMO}}$ and $\mathrm{E}_{\mathrm{LUMO}}$ increases in the sequence: chloramphenicol $<\mathbf{2}<\mathbf{1}$ and chloramphenicol $<\mathbf{2}<\mathbf{1}$, respectively. The trend towards increasing the energy gap is $\mathbf{2}<$ chloramphenicol $<\mathbf{1}$. Experimentally, we have measured the energy gap of the studied compounds, i.e. $4.4 \mathrm{eV}$ for 1 and $4.3 \mathrm{eV}$ for 2 . The computed $\mathrm{E}_{\text {gap }}$ are in reasonable agreement with the experimental data. The small difference between calculated and experimental energy gap is due to that the computed data is in gas phase.

Table 2. HOMO energy ( $\left.\mathrm{E}_{\text {Hомо }}\right)$, LUMO energy ( $\left.\mathrm{E}_{\mathrm{LUMO}}\right)$ and HOMO-LUMO energy gap ( $\left.\mathrm{E}_{\mathrm{gap}}\right)$ in eV, absorption wavelengths $\left(\lambda_{a}\right)^{*}$ in nm of studied compounds.

\begin{tabular}{|c|c|c|c|c|c|c|c|c|c|}
\hline System & $\mathrm{E}_{\text {Номо }}$ & $\mathrm{E}_{\text {LUMO }}$ & $E_{\text {gap }}$ & $E_{\text {gap }}$ & $\lambda_{\mathrm{a}}^{\mathrm{a}}$ & $\lambda_{a}^{b}$ & $\lambda_{a}{ }^{c}$ & $\lambda_{a}^{d}$ & $\lambda_{a}{ }^{e}$ \\
\hline \multirow[t]{3}{*}{1} & -6.31 & -1.27 & 5.03 & 4.40 & 280 & 281 & 287 & 275 & 275 \\
\hline & & & & & 267 & 268 & 271 & 261 & 262 \\
\hline & & & & & 261 & 261 & 266 & 253 & 254 \\
\hline \multirow[t]{3}{*}{2} & -6.72 & -2.31 & 4.41 & 4.30 & 337 & 349 & 349 & 340 & 341 \\
\hline & & & & & 311 & 318 & 321 & 307 & 308 \\
\hline & & & & & 250 & 299 & 300 & 290 & 290 \\
\hline Chloramphenicol & -7.27 & -2.34 & 4.93 & - & & 318 & 325 & 312 & 313 \\
\hline & & & & & & 310 & 320 & 294 & 294 \\
\hline & & & & & & 294 & 307 & 281 & 280 \\
\hline
\end{tabular}

${ }^{\mathrm{a}}$ The calculated absorption wavelengths in gas phase at TD-B3LYP/6-31G* level of theory. ${ }^{\mathrm{b}}$ The calculated absorption wavelengths in DMSO at TD-B3LYP/6-31G* level of theory. ${ }^{\mathrm{c}}$ The calculated absorption wavelengths in DMSO at TD-B3LYP/6-31+G* level of theory. ${ }^{\mathrm{d}}$ The calculated absorption wavelengths in DMSO at TDMPW1PW91/6-31G* level of theory. ${ }^{\text {e}}$ The calculated absorption wavelengths in DMSO at TD-PBE1PBE/6-31G* level of theory. ${ }^{*}$ The experimental maximum absorption wavelengths in DMSO for $\mathbf{1}$ and $\mathbf{2}$ are 306 and $311 \mathrm{~nm}$, respectively.

The calculated absorption wavelengths with and without solvent at TD-B3LYP/6-31G*, TDB3LYP/6-31G*, TD-B3LYP/6-31+G*, TD-MPW1PW91/6-31G* and TD-PBE1PBE/6-31G* level of theories have been presented in Table 2 . The three prominent absorption wavelengths, i.e., 261, 267 and $280 \mathrm{~nm}$ have been observed for 1 without solvent at TD-B3LYP/6-31G* level of theory. At the same level of theory, absorption spectrum has been computed in DMSO and no any effect has been observed on the absorption wavelengths. In the next step, the absorption wavelengths were computed in DMSO at TD-B3LYP/6-31+G* level of theory. We found that by changing the basis set, wavelength being $6 \mathrm{~nm}$ red shifted revealing that basis set has no significant effect. From Table 2, it can be found that TD-MPW1PW91/6-31G* and TDPBE1PBE/6-31G* are also reproducing the same absorption wavelengths for 1 . The computed absorption wavelengths are in good agreement with the experimental evidences. These results showed that the functional and basis set has negligible effect on the absorption wavelengths. Experimentally, we have measured the oscillator strength of $\mathbf{1}$ and $\mathbf{2}$ and then compared with computational data, see supporting information. 


\section{Molecular properties}

The chemical hardness is a measure of resistance to charge transfer while the electronegativity is a measure of the tendency to attract electrons by an atom in a chemical bond which is defined as the negative of the chemical potential in DFT. The electrophilicity index represents the stabilization energy of the system and determines the affinity for the electrons. The smaller hardness value of $\mathbf{2}$ is revealing that it would be good reactive molecule than $\mathbf{1}$ and chloramphenicol. The electrophilicity of $\mathbf{2}$ is also superior to $\mathbf{1}$ and chloramphenicol showing $\mathbf{2}$ would be more susceptible for nucleophilic attack. Total dipole moment imitates the ability of interaction of compounds with the surrounding medium. The dipole moment of $\mathbf{2}$ is higher than 1 revealing that it would have higher ability of interaction with the surrounding medium. It also showed that $\mathbf{2}$ have more binding ability resulting enhance the biological effects. The EA and IP have been calculated at B3LYP/6-31G* level of theory which have been tabulated in Table 3 .

Table 3. The computed reactivity descriptors, ionization potential (IP) and electron affinity (EA) at the B3LYP/6-31G* level of theory.

\begin{tabular}{|c|c|c|c|}
\hline Parameter & $\mathbf{1}$ & $\mathbf{2}$ & Chloramphenicol \\
\hline$\chi$ & 3.79 & 4.52 & 4.80 \\
\hline$\eta$ & 2.52 & 2.21 & 2.46 \\
\hline$\omega$ & 2.85 & 4.62 & 4.69 \\
\hline $\mathrm{S}$ & 0.20 & 0.23 & 0.20 \\
\hline$\omega \mathrm{i}$ & 2.62 & 5.88 & 14.71 \\
\hline$\mu$ & 3.65 & 5.10 & 8.10 \\
\hline $\mathrm{IP}$ & 7.59 & 8.12 & 8.07 \\
\hline EA & 0.06 & 0.82 & 2.00 \\
\hline
\end{tabular}

\section{Molecular electrostatic potential}

The Molecular electrostatic potential (MEP) is used to investigate the molecular interactions. In recent studies, the relative reactivity sites for nucleophilic and electrophilic attack have been intensively studied by MEPs maps [28]. The MEP is associated to total charge distribution as well as endow with the correlation between the molecular properties like partial charges, dipole moments, electronegativity and chemical reactivity of the molecules. The MEPs have been presented in Figure 3. The pink color parts embody the regions of negative electrostatic potential and green parts represent the regions of positive electrostatic potential. The light color parts represent the regions of zero potential. The negative regions of electrostatic potential are related to electrophilic reactivity (the electrophile would attack on this side) while positive regions are associated to nucleophilic reactivity (the nucleophile would attack on positive side). The negative regions are revealing that these sites would be favorable for electrophile's attack while positive regions would be favorable for nucleophile's attack.

\section{QSAR study}

The development of new antibacterial drugs is presently based on structure-activity relationship (SAR), structure-property-activity relationship (SPAR) and quantitative structure-activity relationship (QSAR) studies [29]. The QSAR have frequently been used to determine the correlations between the biological activities and the physicochemical properties of various compounds [30, 31]. The QSAR methods are well known to identify structural blocks responsible for high biological activity [32]. The QSAR study of all the investigated compounds have been carried out and presented in Table 4. The strength of the ion-dipole attractions depends on the size of ion charge and the magnitude of the dipole while inversely to the distance 
between them. The distance between centre of the positive charge and the negative side of the water dipole depend on the size. The hydration energy varies in the reverse order, i.e., negative value increases by decreasing the size. The negative hydration energy value of 2 is -6.22 $\mathrm{kcal} / \mathrm{mol}[33]$.

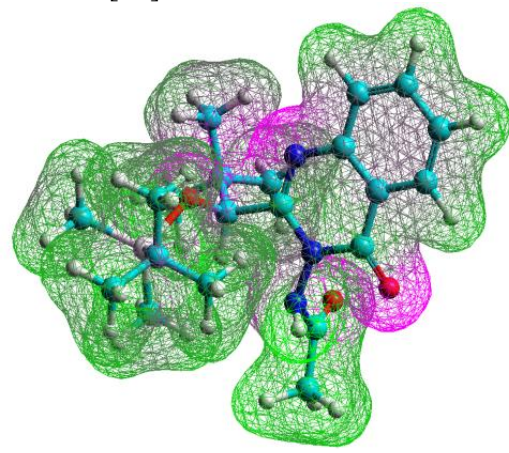

Compound 1

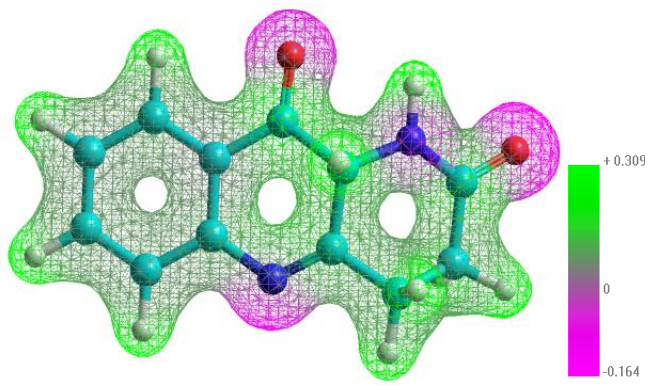

Compound 2

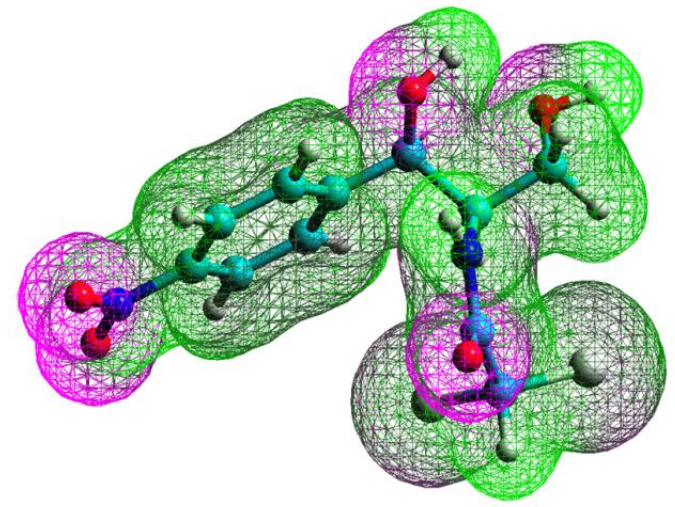

Chloramphenicol

Figure 3. The molecular electrostatic potential surfaces of the studied compounds.

Table 4. The surface area, $\log$ P and hydration energy at DFT level.

\begin{tabular}{|l|l|l|l|}
\hline Parameter & $\mathbf{1}$ & $\mathbf{2}$ & Chloramphenicol \\
\hline Surface Area & $624.70(624.70)$ & $294.23(294.46)$ & $428.22(421.29)$ \\
\hline Volume & $1155.02(1155.02)$ & $613.95(617.99)$ & $783.68(779.59)$ \\
\hline Hydration Energy & $-0.64(-0.64)$ & $-6.22(-6.40)$ & $-14.67(-14.67)$ \\
\hline Log P & $2.96(2.96)$ & $0.82(0.82)$ & $1.26(1.26)$ \\
\hline Refractivity & $107.01(107.01)$ & $57.72(57.72)$ & $72.31(72.31)$ \\
\hline Polarizability & $43.31(43.31)$ & $22.35(22.35)$ & $28.14(28.14)$ \\
\hline Mass & $403.60(403.60)$ & $214.22(214.22)$ & $323.13(214.22)$ \\
\hline
\end{tabular}

The values in parenthesis are by AM1 method.

Lipinski [34-36] stated that any compound which have partition coefficient $(\log \mathrm{P})<5$ with the molecular weight $<500$, molar refractivity from 40-130 having hydrogen bond donor and acceptor sites $<5$ and $<10$, respectively, with no more than one violation would be better as orally active drug. Our synthesized compounds obey these rules. It is expected that $\mathbf{2}$ would be 
more suitable as it has $\log \mathrm{P} 0.82$, molecular weight $<500$, molar refractivity 58 , hydrogen bond donor site 1 and hydrogen bond acceptor sites 3 . In $\mathbf{1}, \log \mathrm{P}$ is 2.96 , molecular weight $<500$, molar refractivity 107, hydrogen bond donor site 1 and hydrogen bond acceptor sites 4 . It showed that $\mathbf{1}$ and $\mathbf{2}$ would be active drugs.

\section{Non-linear optical properties}

The first hyperpolarizabilities $\left(\beta_{\text {tot }}\right)$ of the studied compounds have been calculated at two levels of theories, i.e., HF and DFT. The computed $\beta_{\text {tot }}$ values at HF/6-31G* level of theory have been compared with the DFT/B3LYP/6-31G* and DFT/CAM- B3LYP/6-31G* levels of theories. The $\beta_{\text {tot }}$ is third rank tensor that can be described by $3 \times 3 \times 3$ matrix. The 27 components of the $3 \mathrm{D}$ matrix can be reduced to 10 components due to the Kleinman symmetry [37]. The $\beta_{\text {tot }}$ can be evaluated by using $\mathrm{x}, \mathrm{y}, \mathrm{z}$ components as:

$\beta_{\text {tot }}=\left(\beta_{x}^{2}+\beta_{y}^{2}+\beta_{z}^{2}\right)^{1 / 2}$

Here, $\beta_{\mathrm{x}}=\beta_{\mathrm{xxx}}+\beta_{\mathrm{xyy}}+\beta_{\mathrm{xzz}}$

$\beta_{\mathrm{y}}=\beta_{\mathrm{yyy}}+\beta_{\mathrm{xxy}}+\beta_{\mathrm{yzz}}$

$\beta_{\mathrm{z}}=\beta_{\mathrm{zzz}}+\beta_{\mathrm{xxz}}+\beta_{\mathrm{yyz}}$

The calculated $\beta_{\text {tot }}$ values at all the levels of theories have been presented in Table 5 . The $\beta_{\text {tot }}$ value of chloramphenicol at $\mathrm{HF} / 6-31 \mathrm{G}^{*}$ level of theory is half than that of computed at DFT level of theory. The $\beta_{\text {tot }}$ values of $\mathbf{2}$ are twice of $\mathbf{1}$ at all the levels of theories. At HF/6-31G* level of theory, the $\beta_{\text {tot }}$ of $\mathbf{1}$ and $\mathbf{2}$ are almost five and eight times higher than $\beta_{\text {tot }}$ of urea $(3.728 \times$ $\mathrm{e}^{-31} \mathrm{esu}$ ), respectively. Moreover, at this level of theory computed $\beta_{\text {tot }}$ value of $\mathbf{2}$ is superior to chloramphenicol. The computed $\beta_{\text {tot }}$ are about three and six times higher for $\mathbf{1}$ and $\mathbf{2}$, respectively, than that of urea at DFT/B3LYP/6-31G* level of theory. At DFT/CAM-B3LYP/6$31 \mathrm{G}^{*}$ level of theory, the $\beta_{\text {tot }}$ of $\mathbf{1}$ and $\mathbf{2}$ are also approximately three and six times superior to urea, respectively.

Table 5. The calculated first hyperpolarizabilities $(\beta)$ of the studied compounds in $e^{-31}$ esu.

\begin{tabular}{|l|l|l|l|l|l|l|l|l|}
\hline \multicolumn{3}{|c|}{$H F / 6-31 G^{*}$} & \multicolumn{3}{c|}{$B 3 L Y P / 6-31 G^{*}$} & \multicolumn{3}{c|}{$C A M-B 3 L Y P / 6-31 G^{*}$} \\
\hline $\mathbf{1}$ & $\mathbf{2}$ & Chlor $^{\mathrm{a}}$ & $\mathbf{1}$ & $\mathbf{2}$ & Chlor $^{\mathrm{a}}$ & $\mathbf{1}$ & $\mathbf{2}$ & Chlor $^{\mathrm{a}}$ \\
\hline 17.5 & 29.6 & 24.2 & 12.5 & 21.1 & 58.3 & 11.0 & 22.5 & 41.8 \\
\hline
\end{tabular}

${ }^{\mathrm{a} C h l o r a m p h e n i c o l . ~}$

\section{CONCLUSIONS}

The newly synthesized compounds (1 and 2) were most active against Staphylococcus aureus, Klebsiella pneumonia, Proteus bacilli and Shigella flexneri. Both of the compounds would be active towards pathogenic bacteria. The intra-molecular charge transfer has been observed from HOMO to LUMO in the studied compounds. The computed absorption wavelengths and energy gaps are in good agreement with the experimental data. The functional and basis set has no significant effect on the absorption wavelengths. The smaller hardness value of $\mathbf{2}$ is revealing that it would be better reactive molecule than $\mathbf{1}$ and chloromphenicol. The electrophilicity of $\mathbf{2}$ is also superior to $\mathbf{1}$ and chloromphenicol showing $\mathbf{2}$ would be more susceptible for nucleophilic attack. The higher dipole moment of $\mathbf{2}$ is revealing that it would have higher ability of interaction with the surrounding medium as well as more binding ability resulting enhance the biological effects. QSAR study revealed that the synthesized compounds would be active oral drugs which are obeying the rule of five. Moreover, at this level of theory computed $\beta_{\text {tot }}$ value of $\mathbf{2}$ is superior to chloramphenicol. The computed $\beta_{\text {tot }}$ are about three and six times higher for $\mathbf{1}$ and $\mathbf{2}$, respectively than that of urea. 


\section{ACKNOWLEDGEMENTS}

Authors are thankful to Research Center for Advanced Materials Science, King Khalid University for the support and facilities to carry out the research work.

\section{REFERENCES}

1. Desai, N.C.; Dodiya, A.; Shihory, N. J. Saudi. Chem. Soc. 2013, 17, 259.

2. Rakesh, K.P.; Manukumar, H.M.; Gowda, D.C. Bioorg. Med. Chem. Lett. 2015, 25, 1072.

3. Mohamed, M.A.; Ayyad, R.R.; Shawer, T.Z.; Abdel-Aziz, A.A.M.; El-Azab, A.S. Eur. J. Med. Chem. 2016, 112, 106.

4. Al-Sehemi, A.G. JKAU: Sci. 2006, 18, 47.

5. Al-Sehemi, A.G.; Al-Melfi, M.A.M.; Irfan, A. Struct. Chem. 2013, 24, 499.

6. Irfan, A.; Nadeem, M.; Athar, M.; Kanwal, F.; Zhang, J. Comp. Theor. Chem. 2011, 968, 8.

7. Irfan, A.; Al-Sehemi, A.G.; Asiri, A.M.; Nadeem, M.; Alamry, K.A. Comp. Theor. Chem. 2011, 977, 9.

8. Irfan, A.; Al-Sehemi, A.G.; Muhammad, S.; Chaudhry, A.R.; Al-Assiri, M.S.; Jin, R.; Kalam, A.; Shkir, M.; Asiri, A.M. Comp. Rend. Chim. 2015, 18, 1289.

9. Irfan, A.; Al-Sehemi, A.G. J. Saudi. Chem. Soc. 2014, 18, 574.

10. Irfan, A.; Al-Sehemi, A.G. J. Saudi. Chem. Soc. 2015, 19, 318.

11. Ramalingam, S.; Periandy, S. Spectrochim. Acta A 2011, 78, 835.

12. Barry, A.L. Procedure for testing antimicrobial agents in agar media in Antibiotics in Laboratory Medicine, Corian, V.L. (Ed.), Williams and Wilkins: Baltimore, USA; 1991.

13. James, D.; Lowry, M.; Jaqua, M.J.; Selepak, S.T. Appl. Microbiol. Biotechnol. 1970, $20,46$.

14. Irfan, A.; Muhammad, S.; Al-Sehemi, A.G.; Al-Assiri, M.S.; Kalam, A.; Chaudhry, A.R. J. Theor. Comput. Chem. 2015, 14, 1550027.

15. Irfan, A.; Muhammad, S.; Al-Sehemi, A.G.; Al-Assiri, M.S.; Kalam, A. Int. J. Electrochem. Sci. 2015, 10, 3600.

16. Irfan, A.; Al-Sehemi, A.G.; Muhammad, S.; Chaudhry, A.R.; Kalam, A.; Shkir, M.; ALSalami, A.; Asiri, A.M. J. Saudi. Chem. Soc. 2015, DOI: http://dx.doi.org/10.1016/j.jscs.2014.12.009.

17. Al-Sehemi, A.G.; Irfan, A.; Asiri, A.M.; Ammar, Y.A. Bull. Chem. Soc. Ethiop. 2015, 29, 137.

18. Al-Sehemi, A.G.; Al-Amari, R.S.A.A.; Irfan, A. Bull. Chem. Soc. Ethiop. 2014, 28, 111.

19. Irfan, A. Bull. Chem. Soc. Ethiop. 2014, 28, 101.

20. Liu, J.; Herbert, J.M. J. Chem. Theor. Comput. 2016, 12, 157.

21. Xiao, B.; Li, Y.-c.; Yu, X.-f.; Cheng, J.-b. J. Phys. Chem. A 2015, 119, 11882.

22. Irfan, A.; Zhang, J.; Chang, Y. Chem. Phys. Lett. 2009, 483, 143.

23. Kohn, W.; Becke, A.D.; Parr, R.G. J. Phys. Chem. 1996, 100, 12974.

24. Parr, R.G.; Szentpály, L.V.; Liu, S. J. Am. Chem. Soc. 1999, 121, 1922.

25. Chaudhry, A.R.; Ahmed, R.; Irfan, A.; Shaari, A.; Al-Sehemi, A.G. Mater. Chem. Phys. 2013, 138, 468.

26. Frisch, M.J.; Trucks, G.W.; Schlegel, H.B.; Scuseria, G.E.; Robb, M.A.; Cheeseman, J.R.; Scalmani, G.; Barone, V.; Mennucci, B.; Petersson, G.A.; Nakatsuji, H.; Caricato, M.; Li, X.; Hratchian, H.P.; Izmaylov, A.F.; Bloino, J.; Zheng, G.; Sonnenberg, J.L.; Hada, M.; Ehara, M.; Toyota, K.; Fukuda, R.; Hasegawa, J.; Ishida, M.; Nakajima, T.; Honda, Y.; Kitao, O.; Nakai, H.; Vreven, T.; Montgomery, J.A., Jr.; Peralta, J.E.; Ogliaro, F.; Bearpark, M.; Heyd, J.J.; Brothers, E.; Kudin, K.N.; Staroverov, V.N.; Kobayashi, R.; Normand, J.; Raghavachari, K.; Rendell, A.; Burant, J.C.; Iyengar, S.S.; Tomasi, J.; Cossi, M.; Rega, N.; Millam, J.M.; Klene, M.; Knox, J.E.; Cross, J.B.; Bakken, V.; Adamo, C.; Jaramillo, J.; Gomperts, R.; Stratmann, R.E.; Yazyev, O.; Austin, A.J.; Cammi, R.; Pomelli, C.; 
Ochterski, J.W.; Martin, R. L.; Morokuma, K.; Zakrzewski, V.G.; Voth, G.A.; Salvador, P.; Dannenberg, J.J.; Dapprich, S.; Daniels, A.D.; Farkas, Ö.; Foresman, J.B.; Ortiz, J.V.; Cioslowski, J.; Fox, D.J. Gaussian 09, Revision A. 01, Gaussian Inc.: Wallingford, CT, 2009.

27. Froimowitz, M. Biotechniques 1993, 14, 1010.

28. Murray, J.S.; Sen, K. Molecular Electrostatic Potentials: Concepts and Applications, Elsevier Science B V: Amsterdam, The Netherlands; 1996.

29. Narasimhan, B.; Belsare, D.; Pharande, D.; Mourya, V.; Dhake, A. Eur. J. Med. Chem. 2004, 39, 827.

30. Chang, Y.-S.; Wang, B.-C.; Yang, L.-L. J. Chin. Chem. Soc. 2010, 57, 916.

31. Liao, H.-R.; Chang, Y.-S.; Yang, L.-L.; Lin, Y.-C.; Chou, Y.-M.; Wang, B.-C. J. Chin. Chem. Soc. 2006, 53, 1251.

32. Zahradnik, P.; Foltinova, P.; Halgas, J. SAR QSAR Environ. Res. 1996, 5, 51.

33. Kotz, J.C.; Treichel, P.M.; Townsend, J. Chemistry and Chemical Reactivity, Thomson Higher Education: Belmont, CA 94002-3098; 2009.

34. Lipinski, C.A. Drug Discov. Today: Technol. 2004, 1, 337.

35. Lipinski, C.A.; Lombardo, F.; Dominy, B.W.; Feeney, P.J. Adv. Drug Del. Rev. 1997, $23,3$. 36. Lipinski, C.A.; Lombardo, F.; Dominy, B.W.; Feeney, P.J. Adv. Drug Del. Rev. 2001, 46, 3. 37. Kleinman, D.A. Phys. Rev. 1962, 126, 1977. 